\title{
Contingent Negative Variation and response to antidepressants
}

\author{
Papart, P., Ansseau, M. and Timsit-Berthier, M. \\ Psychiatric Unit, C.H.U. du Sart Tilman, B-4000 Liège, Belgium
}

Contingent Negative Variation (CNV) is an event-related potential that develops during a simple experimental situation with a warning and an imperative stimulus.

In depression, CNV studies have shown abnormalities in both amplitude and duration (Timsit-Berthier et al, 1987). A decrease or an increase in amplitude have been reported during depressive episodes and normalization with clinical recovery (Papart et al, 1990).

From animal and neuroendocrine findings, we hypothetized that low CNV amplitude are related to low catecholaminergic activity while high CNV amplitude may be due to low serotonergic activity (Timsit-Berthier et al, 1981).

To test this hypothesis, we studied the response to selective antidepressants (NA or 5-HT) in two groups of depressed patients, with low or high CNV amplitude. Low CNV amplitude patients had a better response with NA-antidepressants and high CNV amplitude patients were better improved with 5-HT-antidepressants.

These results will be discussed and may represent considerable interest in the selection of drug treatment in depression.

\section{References}

Timsit-Berthier, M., Mantanus, H., Ansseau, M., Devoitille, J.M., Dal Mas, A. and Legros, J.J., 1987, Contingent Negative Variation in major depressive patients. In: Johnson, R. Jr., Rohrbaugh, J.W. and Parasuraman, R. (eds), Current Trends in Event-Related Potential Research (EEG Suppl. 40). Elsevier Science Publishing, pp. 762.

Papart, P., Ansseau, M., Timsit, M. and Timsit-Berthier, M., 1990, VCN et épisodes dépressifs: corrélations électro-cliniques. Neurophysiol. Clin., 20, 28S.

Timsit-Berthier, M. and Timsit, M., 1981, Toward a neurochemical interpretation of CNV in psychiatry: Some preliminary results in depressive patients. In: Kemali, D. and Perris, C. (eds), Advances in Biological Psychiatry, vol. 6, Karger, Basel, pp. $165-172$.

\section{The role of serotonin in behavioural abnormalities}

\author{
Marazziti, D., Rotondo, A., Palego, L. and Conti, L. \\ Institute of Psychiatry, University of Pisa, via Roma 67, 56100 Pisa, Italy
}

Aggression is a complex behavioural pattern, probably resulting from an imbalance of different neurotransmitters: however, the serotonin (5HT) system appears to play a central role in the control of aggression.

The aim of this study was to evaluate two peripheral 5 HTergic markers, ${ }^{3} \mathrm{H}$-imipramine $\left({ }^{3} \mathrm{H}\right.$-IMI) binding and $5 \mathrm{HT}$ uptake in platelet membranes of a group of severely aggressive subjects (A) institutionalized since the childhood for mental retardation, as compared with suicide attempters $(S)$ and healthy controls $(H)$.

The maximum binding capacity (Bmax, fmol/mg protein) of ${ }^{3} \mathrm{H}$-IMI to platelet membranes was $654 \pm 199$ (A), $476 \pm$ $149(\mathrm{~S})$ and $995 \pm 240(\mathrm{H})$, statistically lower in (A) and (S) than in (H). In addition, a statistically significant difference was observed between Bmax values of aggressive subjects and those of suicide attempters. The results concerning the maximum velocity (Vmax) of 5HT uptake were similar. No changes in the dissociation constant (Kd) of IMI binding or in the Michaelis constant of 5HT uptake were observed. 